\title{
Hallucinogen-induced behaviors of free-moving chimpanzees
}

\author{
KIRK J. BROWER and RONALD K. SIEGEL \\ Department of Psychiatry and Biobehavioral Sciences, University of California, \\ Los Angeles, California 90024
}

\begin{abstract}
The effects of the hallucinogen N,N-dimethyltryptamine (DMT) on the behavior of two island groups of four champanzees each were studied. One target animal from each group was selected for treatment and individual and social behaviors were scored according to a quantitative observational system. Low doses of DMT $(.5-3.0 \mathrm{mg} / \mathrm{kg})$ caused dose-dependent increases in duration of vocalization, fear grimace, and locomotion. Higher doses $(4.0 \mathrm{mg} / \mathrm{kg})$ tended to decrease these behaviors as well as others such as self-grooming. Social aggregation tended to decrease with increasing doses, and social interactions between target animals and others were rare. Results tended to support the hypothesis that hallucinogens increase social spacing and isolation.
\end{abstract}

A number of laboratory studies have demonstrated that characteristic and often dramatic behavioral changes occur in nonhuman primates following treatment with hallucinogens (see review by Siegel \& Jarvik, 1975). Hallucinogen-treated primates have been observed to jump, scream, whimper, and grimace; touch, scratch, or wipe their heads and faces; exhibit hyperexcitability and fear; cover their eyes with their hands; grasp at imaginary objects in the air; and run backward while waving their hands in front of their faces (Baldwin, Lewis, \& Frost, 1957; Klüver, 1966; Lagutina, Laricheva, Mil'shtein, \& Norkina, 1964; Reynolds, Barker, \& Joffe, 1968). Siegel, Brewster, and Jarvik (1974) have developed an objective technique for quantitatively scoring such behaviors. Accordingly, hallucinogens (LSD and DMT) could be distinguished from other drugs (d-amphetamine and chlorpromazine) by an increased frequency of such behaviors as spasms, stereotypy, rocking, fear grimaces, tracking, inappropriate behavior, and a decreased amount of vocalization and exploration time. This observational method has recently been shown to be sensitive enough to detect dose-response curves with DMT-treated monkeys (Brewster, Siegel, Johnson, \& Jarvik, 1976).

The robust behavioral changes that occur in individual nonhuman primates treated with hallucinogens, coupled with unobtrusive observational methods, suggest further extension of these studies to social groups in more natural (nonlaboratory) habitats. The following initial study was designed to explore these areas.

This research was supported in part by USPHS Grant MH23880 to Murray E. Jarvik, MD, PhD. We thank S. Craig, M. Tennet, D. Dooley, P. Quinn, and J. Kobrin for cooperation and assistance at Lion Country Safari. We thank P. McGinnis of the Standard Outdoor Primate Facility for advice and criticism in the planning of this study. Reprints may be obtained from R. K. Siegel, Psychopharmacology Unit, Research Trailer 350 , 530/151D, Brentwood VA Hospital, Los Angeles, California 90073.

\section{METHOD}

\section{Subjects}

Subjects were four male and four female chimpanzees (Pan troglodytes) that lived on two outdoor islands of a small lake located in a park owned and operated by Lion Country Safari, Inc., Laguna Hills, California. The two islands, each approximately $300 \mathrm{sq} \mathrm{m}$ in area, were within visual and vocal range of each other. Four of the chimps (one male and three females) lived on the island designated as North Island, and the other four chimps (three males and one female) lived on South Island. All chimps were fully mature adults except for a North Island adolescent female and a South Island juvenile male. Target animals, selected for representative social interaction, were an adult female from North Island (Alice) and an adult male from South Island (OJ), and each weighed approximately $45 \mathrm{~kg}$. Subjects were fed daily each morning by a ranger who threw Purina Monkey Chow and lettuce onto the islands from a boat. Subjects also received evening supplements of fresh fruits and drank freely from the water surrounding the islands. Each island contained many large rocks, two trees for climbing, and one wooden shelter box large enough for three or four chimpanzees. Because chimps cannot swim, they were confined to their islands, although free to move about.

\section{Drugs}

DMT was the hallucinogen of choice, as its relatively short duration of action minimized the risk of accidental drowning yet induced behavioral effects similar to the prototypical hallucinogen LSD (cf. Meldrum \& Naquet, 1971). Doses of DMT ranged from .5 to $4.0 \mathrm{mg} / \mathrm{kg}$ and were administered in a constant volume of $1 \mathrm{ml}$ acidified (acetic acid) saline, except for the highest dose which required $2 \mathrm{ml}$ of acidified saline for dissolution. Drugs were injected intramuscularly via a dart shot from a $\mathrm{CO}_{2}$-powered rifle (Palmer Chemical Equipment Company, Douglasville, Georgia) at a range of about $10 \mathrm{~m}$. The dart had a 17-ga .75-in. $(1.9 \mathrm{~cm})$ long needle, which was barbed in order to prevent a "bounce-out" and thereby insure that the animal received the total volume. Treatment with $1 \mathrm{ml}$ of acidified saline was designated as the control for effects caused by injection procedures.

\footnotetext{
Apparatus

Observations were made from inside a parked vehicle on the lake's shore using a pair of Bushnell Custom $(10 \times 50 \mathrm{~mm}$, 7-deg field) binoculars at a distance of about $32 \mathrm{~m}$ to the center of the island. Behaviors were coded in digital format and were
} 
recorded during observational periods using a Model DAK-8VC Datamyte portable recorder (Electro/General Coporation, Hopkins, Minnesota). This instrument resembled a touch-tone telephone and the observer entered behavioral codes via a 12button keyboard. Depression of keys produced characteristic electrical signals which were automatically recorded onto a magnetic tape cartridge. A Teletype printout of raw data was later made from the tape for analysis of frequencies and durations of behaviors.

\section{Behavioral Scoring Categories}

The classification of behaviors was chosen after review of the literature (Davenport \& Rogers, 1970; Hill, 1966; Mason, 1970; Mitchell, 1970; Reynolds, 1970; van Lawick-Goodall, $1968,1972)$ and preliminary observations of subjects. Behaviors were chosen on the basis of their probable sensitivity to hallucinogenic drugs (Brewster et al., 1976; Siegel et al., 1974). The final categories of social and individual behaviors are defined below. They were recorded in terms of frequency, duration, sequence, and identity of interacting animals.

Individual behaviors. Locomotion-moving the whole body from one place to another; this included walking, running, climbing, and swinging. Exploration-sensory examination of or orientation to objects in the environment. Feeding-eating or drinking. Inappropriate-any unusual behavior not often seen in normal chimpanzees. Coprophagy-eating of excrement. Vocalization-sounds or calls including panthoots, screams, grunts, or whimpers. Yawn-opening and closing of mouth. Fear grimace-lips pulled back to expose lower and usually upper teeth. Stereotypy-movements other than rocking that were performed repeatedly and continuously. Rocking-repetitive forward and backward or side-to-side movement of body. Self-grooming-picking or pulling at the skin or hair with hands or mouth. Threat-displays such as jumping up and down while vigorously stamping the ground with feet and hands, bipedal swaying from foot to foot, hurling objects, and charging. Threats classified as individual behavior were not specifically directed at other chimps. Tracking-following with the eyes and/or hands an object not visible to the observer.

Social behaviors. Locomotion-leading or following another animal. Inspection-tactile examination of the genital area of a female. Copulation-pelvic thrusting and intromission. Grooming-picking or pulling at the skin or hair of another. Threat-displays (described above) that were directed toward another chimp. Attack-included hitting, biting, or wrestling with another animal. Contact-included all forms of physical contact except inspection, copulation, grooming, and attack behavior; behaviors that occurred in greeting, submissive, reassurance, and play contexts such as embracing, touching, hand holding, and kissing. Play behavior (hitting, mock biting, tickling, and wrestling) was usually distinguished from aggressive behavior by its longer duration, absence of piloerection and compressed lips face, and presence of "play face" (van Lawick-Goodall, 1972).

Other measures. Aggregation-a measure of social spacing. Two animals were defined as aggregated when they were within arm's reach of one another. Out of sight-the animal had locomoted to a place on the island that was not visible to the observer.

\section{Procedure}

Each island was observed from a particular vantage point on the lake's shore and these two positions were maintained throughout the experiment. Prior to drug manipulations, subjects were observed for a total of over $100 \mathrm{~h}$, during which behavioral categories were developed and preliminary observations were recorded. One animal from each island was then chosen as the target for drug administration, and these same two animals (Alice and OJ) were used each time drugs were given. Treatment sessions were spaced by at least 1 -week intervals. OJ received DMT doses of $.5,2.0,3.0$, and $4.0 \mathrm{mg} / \mathrm{kg}$ on successive weekly treatment days, while Alice received saline, $2.0 \mathrm{mg} / \mathrm{kg}$ DMT, no treatment, and $4.0 \mathrm{mg} / \mathrm{kg}$ DMT on the same treatment days. Additional control sessions were planned but not run due to difficulties arising from target animals evading rifle-injection procedures.

On a given treatment day, all animals were fed at their usual time (8:00-9:00 a.m.). Ten minutes of predrug baseline observations of a target animal were subsequently recorded with the Datamyte. Following this, a preinjection period ensued during which a ranger, positioned in a boat off the island's shore, located and "darted" the target animal using the rifle previously described. Starting from the time of injection, 30 min of Datamyte observations of the target animal were recorded, followed by $30 \mathrm{~min}$ of written commentary. The procedure was then repeated with the target animal on the other island. The observer was "blind" to the identity of the drug and dose.

\section{RESULTS}

Table 1 shows the percentage of total observation time that each target animal engaged in selected behaviors during baseline and drug sessions. Baseline scores were calculated by combining baseline obser-

Table 1

Behavior Scores as a Function of Drug Treatment

\begin{tabular}{|c|c|c|c|c|c|c|c|c|c|}
\hline \multirow[b]{3}{*}{ Behavior } & \multicolumn{5}{|c|}{ OJ } & \multicolumn{4}{|c|}{ Alice } \\
\hline & \multirow[b]{2}{*}{ Baseline } & \multicolumn{4}{|c|}{ DMT Dosage $(\mathrm{mg} / \mathrm{kg})$} & \multirow[b]{2}{*}{ Baseline } & \multirow[b]{2}{*}{ Saline } & \multicolumn{2}{|c|}{ DMT Dosage $(\mathrm{mg} / \mathrm{kg})$} \\
\hline & & .5 & 2.0 & 3.0 & 4.0 & & & 2.0 & 4.0 \\
\hline \multicolumn{10}{|l|}{ Individual } \\
\hline Threat & .4 & 0 & 2.5 & 0 & 0 & 0 & 0 & .2 & 0 \\
\hline Vocalization & $0^{.4}$ & .5 & 2.2 & 10.6 & 0 & 0 & 0 & $0^{.2}$ & .2 \\
\hline Fear Grimace & 0 & 0 & 5.6 & 6.5 & 0 & 0 & 0 & 0 & $0^{.2}$ \\
\hline Exploration & 0 & 18.3 & 0 & 4.6 & .3 & 0 & 0 & 1.2 & 0 \\
\hline Self-Grooming & 0 & 11.5 & 6.1 & 1.6 & 3.2 & 1.0 & 14.4 & 7.4 & .1 \\
\hline Locomotion & 16.5 & 18.1 & 26.4 & 67.9 & 65.8 & 11.8 & 9.6 & 14.0 & 7.2 \\
\hline Inappropriate & 0 & 0 & 0 & 0 & 0 & 0 & 0 & 0 & 3.6 \\
\hline \multicolumn{10}{|l|}{ Social } \\
\hline Lead & 0 & 0 & 0 & 0 & 0 & 0 & 0 & 31.3 & 0 \\
\hline Threatened & 0 & 0 & .2 & 0 & 0 & 0 & 0 & 0 & 2 \\
\hline Contacting & 0 & 0 & 0 & 0 & 0 & 0 & 0 & .2 & .1 \\
\hline \multicolumn{10}{|l|}{ Other } \\
\hline Aggregation & 1.8 & 25.2 & 31.2 & 7.3 & 1.1 & 14.0 & 66.3 & 32.5 & 17.0 \\
\hline
\end{tabular}


vations from all treatment days. Frequency and sequence data are not discussed in this report.

\section{OJ}

Table 1 shows that under some doses of DMT (2.0 and $3.0 \mathrm{mg} / \mathrm{kg}$ ) increases in threat behavior, vocalization, and fear grimaces were observed. All of these behaviors were found to have occurred within the first few minutes after injection, which suggests reactions to dart impact and subsequent removal. (Target animals always removed their own darts within a few minutes after injection.) Indeed, self-grooming, which was always focused on the site of injection, was increased above baseline during DMT treatment, although the highest increases occurred with the lowest doses of drug $(.5$ and $2.0 \mathrm{mg} / \mathrm{kg}$ ). Furthermore, the increases in exploration during treatment with .5 and $3.0 \mathrm{mg} / \mathrm{kg}$ DMT were associated with periods of olfactory and oral examination of the dart.

A dose-dependent increase in locomotion was also observed. Extremely high scores of $67.9 \%$ and $65.8 \%$ were obtained with respective doses of 3.0 and $4.0 \mathrm{mg} / \mathrm{kg}$ of drug as compared to a baseline score of $16.5 \%$. High scores for aggregation, $25.2 \%$ and $31.2 \%$, were obtained with .5 and $2.0 \mathrm{mg} / \mathrm{kg}$ DMT, respectively. These scores were well above the baseline value of $1.8 \%$. Aggregation scores returned to the baseline value at higher doses. It is noteworthy that decreases in aggregation and self-grooming at higher doses were associated with increases in locomotion. In spite of large increases in aggregation (i.e., decreases in social spacing), social interactions were few.

\section{Alice}

The most salient drug-induced behaviors in Alice were increased aggregation, locomotion, and self-grooming. Grooming decreased with the higher dose of DMT but was well above the baseline level with saline and $2.0 \mathrm{mg} / \mathrm{kg}$ DMT (Table 1). Grooming was always of the injection site. Locomotion increased with $2.0 \mathrm{mg} / \mathrm{kg}$ but decreased with $4.0 \mathrm{mg} / \mathrm{kg}$ DMT. In addition to individual locomotion, an extremely high amount (31.3\%) of social locomotion occurred with Alice as leader during treatment with $2.0 \mathrm{mg} / \mathrm{kg}$ DMT. Aggregation was always above baseline $(14.0 \%)$ but was highest for saline treatment (66.3\%) and, as with OJ, returned to the baseline level with the highest DMT dose $(17.0 \%$ with $4.0 \mathrm{mg} / \mathrm{kg})$. Aggregation was not usually associated with social interactions, which were minimal outside of the leading behavior just described.

Inappropriate behaviors for Alice included sudden, fast scratching or wiping movements and, on one occasion, waving a hand in front of the face for a very brief time.

\section{DISCUSSION}

The most apparent aspect of the findings is that target animals responded to DMT with dose-dependent changes (as compared to baseline) in locomotion, self-grooming, and aggregation. The high aggregation scores for both animals following treatment with saline or the lower doses of DMT probably resulted from injection procedures per se. Apparently, the darting of the target animal represented a novel change in the environment for the other nondrugged members of the group, and the increased aggregation reflected a normal orientation to the source of novelty. Indeed, observations indicated that the dart was the focal point of most aggregation, and the other animals would approach the target animal in order to view the curious metal object in its possession. Decreases in aggregation at higher DMT doses, however, were apparently due to druginduced changes in the target animal itself. With $O J$, the increase in individual locomotion at higher DMT doses competed with aggregation behavior since, as preliminary observations indicated, the other chimps on South Island were not likely to follow OJ around. Alice, when treated with $4.0 \mathrm{mg} / \mathrm{kg}$ DMT, spent most of her time in a tree, where the other animals could not easily come within reach of her, even though they often congregated at the base of that tree.

The position that Alice took in the tree may have represented a deliberate attempt to isolate herself from the other animals. Similarly, the increased locomotion observed in OJ may have represented his unique attempt both to isolate himself and to respond to the general excitatory properties of DMT. These observed isolation effects at the higher doses of DMT are consistent with the findings for lower species reported by Siegel (1971) and also with the observations of a male chimpanzee treated with LSD (Baldwin et al., 1957). Similarly, Dorr and Steinberg (1976) reported an increase in flight behavior in mice treated with $\Delta^{9}$-tetrahydrocannabinol in response to investigations from nontreated mice, and suggested that this result could be explained by drug-induced hypersensitivity to external auditory and tactile stimuli. Alternatively, Siegel (1973) has suggested that hallucinogen-treated animals tend to isolate themselves from social stimulation because of the intense internal stimulation and stimuli (such as hallucinations) presumably induced by these drugs. Whatever the mechanism by which hallucinogens increase isolation, it should be noted that in the present study aggregation never dropped appreciably below baseline levels, although this may have been because baseline levels were low to begin with or because of the novelty created by injection procedures.

As with aggregation, self-grooming increased following injection but appeared to be inhibited by drug effects at high DMT doses. With OJ, the drug-induced increase in locomotion at high DMT doses was incompatible with the grooming response; this animal was frequently observed to stop walking, examine his injection site, and then resume walking, as if he could not "make up his mind" whether to walk or groom. Such "abortive grooming" is similar to hallucinogen-induced effects in cats (Jacobs, Toulson, \& Stern, 1976). Alice, after treatment with 2.0 and $4.0 \mathrm{mg} / \mathrm{kg} \mathrm{DMT}$, performed quick, sudden scratching movements which were similar, if not identical, to the "wiping" movements of rhesus monkeys treated with mescaline (Kluver, 1966). The "wiping" movements may have been responses to internal stimuli (e.g., paresthesia) induced by the hallucinogen, which interfered with normal grooming.

The dramatic hallucinogen-induced changes, often reported in the literature with primates, were conspicuously absent in this study. Although Alice exhibited some inappropriate behavior, the characteristic spasms, tracking, and bizarre postures did not occur. It may be speculated that, when primates are tested singly in laboratory environments and cages, the social isolation and restraint function to channel the hallucinogeninduced arousal of the autonomic nervous system into inappropriate behaviors. Conversely, testing in more natural social groupings and habitats, as in this study, function to attenuate inappropriate behaviors by providing more normal locomotor outlets for the excitation and arousal. Laboratory primates often react to hallucinogens by climbing and bumping into 
cage walls, "trying to escape," and appearing "frightened" or "panicked." These free-moving chimpanzees, when provided with the opportunity "to escape" within the boundaries of the island, responded to DMT with increased locomotion and social isolation, with little or no evidence of fear or panic. Such drug-environment interactions may also help to explain the well-known dependence of human hallucinogenic experiences on set and setting.

\section{REFERENCES}

Baldwin, M., Lewis, S. A., \& Frost, L. L. Perceptual interference after cerebral ablation. Perceptual and Motor Skills, 1957, 7, 45-48.

Brewster, J. M., Siegel, R. K., Johnson, C. A., \& Jarvik, M. E. Observational determination of dose-response curves in hallucinogen-treated monkeys. International Pharmacopsychiatry, 1976, 11, 102-108.

Davenport, R. K., \& Rogers, C. H. Differential rearing of the chimpanzee. In G. H. Bourne (Ed.), The chimpanzee (Vol. 3). New York: Kargel, Basel, 1970.

DorR, M., \& STEINBERG, H. Effects of $\Delta^{9}$. tetrahydrocannabinol on social behaviour in mice. Comparison between two vehicles. Psychopharmacology, 1976, 47, 87-91.

HrLl, C. A. Coprophagy in apes. The International Zoo Yearbook, 1966, 6, 251-257.

JACoBs, B. L., Toulson, M. E., \& Stern, W. C. An animal behavior model for studying the actions of LSD and related hallucinogens. Science, 1976, 194, 741-743.

KLÜVER, H. Mescal and mechanisms of hallucinations. Chicago: University of Chicago Press, 1966.

Lagutina, N. I., Laricheva, K. A., Mil'shtein, G. I., \& NorkinA, L. N. Effect of D-lysergic acid diethylamide on higher nervous activity in baboons. Federal Proceedings Translation Supplement, 1964, 23, 737-740.

MAson, W. A. Chimpanzee social behavior. In G. H. Bourne (Ed.), The chimpanzee (Vol. 2). New York: Kargel, Basel, 1970.

MeldRum, B. S., \& NAQUet, R. Effects of psilocybin, dimethyltryptamine, mescaline, and various lysergic acid derivatives on the EEG and on photically induced epilepsy in the baboon (Papio papio). Electroencephalography and Clinical Neurophysiology, 1971, 31, 563-572.

Mitchell, G. Abnormal behavior in primates. In L. A. Rosenblum (Ed.), Primate behavior: Developments in field and laboratory research. (Vol. 1). New York: Academic Press, 1970.

Reynolds, H. H., Barker, L. M., \& Joffe, M. H. Effect of 2,5-dimethoxy-4-methyl-amphetamine (DOM) on psychophysical responding by a chimpanzee. Perceptual and Motor Skills, 1968, 27, 1315-1320.

ReYNolds, P. C. Social communication in the chimpanzee: A review. In G. H. Bourne (Ed.), The chimpanzee (Vol. 3). New York: Kargel, Basel, 1970.

SiEgel, R. K. Studies of hallucinogens in fish, birds, mice and men: The behavior of "psychedelic" populations. In O. Vinar, Z. Votava, \& P. B. Bradley (Eds.), Advances in neuro-psychopharmacology. Amsterdam: North Holland, 1971.

SIEGEL, R. K. An ethologic search for self-administration of hallucinogens. The International Journal of the Addictions, 1973, 8, 373-393.

Siegel, R. K., Brewster, J. M., \& Jarvik, M. E. An observational study of hallucinogen-induced behavior in unrestrained Macaca mulatta. Psychopharmacologia, 1974, 40, 211-223.

Siegel, R. K., \& JARviK, M. E. Drug-induced hallucinations in animals and man. In R. K. Siegel \& L. J. West (Eds.), Hallucinations: Behavior, experience, and theory. New York: John Wiley, 1975.

VAN Lawick-Goodall, J. The behaviour of free-living chimpanzees in the Gombe Stream Reserve. Animal Behaviour Monographs, 1968, 1, 161-311.

VAN LAWICK-GoodALL, J. A preliminary report on expressive movements and communication in the Gombe Stream chimpanzees. In P. Dolhinow (Ed.), Primate patterns. New York: Holt, Rinehart, \& Winston, 1972.

(Received for publication November 29, 1976.) 